\title{
CHOICE AND COMPLEXATION OF TECHNIQUES AND TOOLS FOR ASSESSMENT OF NPP I\&C SYSTEMS SAFETY
}

\author{
Oleg Illiashenko \\ MS - student, \\ National Aerospace University "KhAI” \\ o.illiashenko@csac.khai.edu
}

\author{
Eugene Babeshko \\ PhD - student, \\ National Aerospace University "KhAI” \\ e.babeshko@csac.khai.edu
}

\section{INTRODUCTION}

There are a lot of techniques to analyze and assess safety of NPP I\&C systems (e.g. FMEA and its modifications, FTA, HAZOP, RBD, Markov Models, etc.). And also there are a lot of modifications of existing techniques. And there are sets of tools which support these methods. Their quantity is constantly increasing. The use of appropriate software tools can increase the integrity of the development process, and hence product reliability and safety, by reducing the risk of introducing faults in the process. Criteria for selection of software tools should be developed and prioritized so as to be able to make an appropriate choice. Known techniques of safety assessment, as well as problems of choice and complexation of these techniques are analyzed. The purpose of this work is to develop a methodology (based on new type of safety cases) of choice of the most appropriate technique for safety analysis and tool which could cover safety analysis requirements for a particular task. Also one of the aims of this paper is to create a software tool for decision making in choice.

\section{CRITERIA FOR ANALYSIS AND COMPARISON OF TOOLS\&TECHNIQUES FOR SAFETY ASSESSMENT}

In paper the following criteria for analysis of Tools and Techniques are used: compliance to international, state, and industrial standards/guidance/programs; experience of application in industry; methods used for assessment of system NPP I\&C R\&S; tool architecture/framework; reporting; vendor support, etc. Features of criteria are described

\section{TECHNIQUE OF CHOOSING AND COMPLEXATION}

Results of analysis of Tools\&Techniques are presented in matrix form ("tool-criterion").Example of matrix for choosing for FMECA-based safety assessment is described. Main procedures of assessment and choosing of tools are the following: building of Table; Boolean matrix isolation; select the optimal set of task solutions; selection from optimal set of solutions by criterion.

Features of complexation of different safety assessment techniques are described.

\section{CASE STUDY}

The proposed technique is implemented as special tool for decision making. This tool consists of database of tools and techniques, database of standards, logic modules of T\&T choosing, graphical interface, etc.

\section{IMPLEMENTATION OF TECHNIQUE AND TOOL}

The proposed technique was used for development of RPC Radiy company standard CStd 66 that contains requirements and procedures of FMECA analysis of developed and produced NPP I\&C systems based on RADIY platform.

\section{CONCLUSIONS}

Paper proposes an approach of "technique of techniques' choosing" for NPP I\&C systems R\&S assessment. Also tool "Support+Plus" that realized methodology of decisionmaking was developed. It is planned to create more universal decision making system based on described tool.

\section{REFERENCES}

Babeshko, E., et al, 2009, Radioelectronic and computer systems, Vol. 40, pp 60-64.

Illiashenko, O., et al, 2010, Radioelectronic and computer systems, Vol. 48, pp 283-287.

Kharchenko, V., et al, 2010, ICAPP'10

Goble, W, 2010, "Control Systems Safety Evaluation and Reliability", 3rd ed., ISA Press, 550.

Yangyang, Yu, et al, 2006, RAMS-2006, pp 588-593.

Bowles, J., et al, 1990, Annual Reliability and Maintainability Symposium, pp 450-455.

Brall, A., et al, 2007, RAMS-2007, pp 119-124.

Li, M., et al, 2008, RAMS-2008, pp 86-90.

McEllin, M.,2010, SCSC Newsletter,Volume 20, Number10, pp 5-7.

Rae, A., 2010, SCSC Newsletter, Volume 20, Number 10, pp 8-11.

Bishop, P.,et al, 1998, Industrial Perspectives of SafetyCritical Systems, SCSS, pp 2-10.

RPC Radiy Company Standard, CStd. 66, Reliability Analysis. Failure Modes, Effects and Criticality Analysis (FMECA), 2010, 30 p. 


\section{CHOICE AND COMPLEXATION OF TECHNIQUES AND TOOLS FOR ASSESSMENT OF NPP I\&C SYSTEMS SAFETY}

\author{
Oleg Illiashenko \\ MS - student, \\ National Aerospace University "KhAI”, \\ Kharkov, 17 Chkalov st., Ukraine 61070 \\ Phone: +380954676066 \\ o.illiashenko@csac.khai.edu
}

\author{
Eugene Babeshko \\ PhD - student, \\ National Aerospace University "KhAI", \\ Kharkov,17 Chkalov st.,Ukraine 61070 \\ Phone:+380662998303 \\ e.babeshko@csac.khai.edu
}

Keywords: Reliability, Safety Analysis, Tools, FMECA, Safety Case.

\begin{abstract}
There are a lot of techniques to analyze and assess reliability and safety of NPP Instrumentation and Control (I\&C) systems (e.g. FMEA - Failure Modes and Effects Analysis and its modifications, FTA - Fault Tree Analysis, HAZOP - Hazard and Operability Analysis, RBD Reliability Block Diagram, Markov Models, etc.) and quantity of tools based on these techniques is constantly increasing. Known ways of safety assessment, as well as problems of their choice and complexation are analyzed.

Objective of the paper is the development of general "technique of techniques choosing" and tool for support of such technique.

The following criteria are used for analysis and comparison and their features are described:

- compliance to normative documents;

- experience of application in industry;

- methods used for assessment of system NPP I\&C safety;

- tool architecture/framework;

- reporting;

- vendor support, etc.

Comparative analysis results of existing T\&T - Tools and Techniques for safety analysis are presented in matrix form ("Tools-Criterion") with example.

Features of complexation of different safety assessment techniques (FMECA, FTA, RBD, Markov Models) are described.

The proposed technique is implemented as special tool for decision-making.

The proposed technique was used for development of RPC Radiy company standard CS 66. This guide contains requirements and procedures of FMECA analysis of developed and produced NPP I\&C systems based on RADIY platform.
\end{abstract}

\section{INTRODUCTION}

\subsection{Motivation}

Reliability and safety are the most important attributes of any critical I\&C system. Safety assessment is anticipated by requirements of national, international, industrial standards and other normative documents.

Safety analysis is an important and quite complicated part of critical NPP systems development through the life cycle. There are several types of risks which could be caused by improper analysis: risk of overestimation and risk of low estimation.

There are a lot of techniques to analyze and assess safety of NPP I\&C systems and also there are a lot of modifications of existing techniques. For example just for FMEA there are several levels of analysis: component, structure, stage, etc. And there are sets of tools which support these methods. Their quantity is constantly increasing. The use of appropriate software tools can increase the integrity of the development process, and hence product reliability and safety, by reducing the risk of introducing faults in the process. Criteria for selection of software tools should be developed and prioritized so as to be able to make an appropriate choice.

Nowadays in safety analysis there is a problem of choice of the most appropriate analysis technique (and tool which supports this technique). This problem is quite complicated to solve because of the following factors: constraints (regulatory documents, e.g. standards, procedures, etc), different output data (predicted results of analyses may vary even when different techniques are used to analyze the same object). Nowadays there is no universal tool which supports all techniques for safety analysis and satisfies all requirements of normative documents.

As previously said quantity of safety analysis techniques is very high, these techniques are complex and relation between them is not easily traceable. The same problem is also urgent for safety software tools. Not always software tool follows all the principles of international and industry normative documents, so analysis result is not always unprejudiced. As a uniting technology a new safety case methodology has to be proposed.

This paper is the beginning of "choice problem" solving regarding to reliability and safety analysis methods and tools. 


\subsection{Analysis of related works}

Known works related to the problem are divided into following groups: (1) Combined use of tools and techniques for safety analysis; (2) Requirements to safety analysis application; (3) Safety Case development and application.

\subsubsection{Combined use of tools and techniques for safety} analysis

The problem of multistage reliability and safety analysis, possibilities of combined usage of reliability and safety analysis techniques for safety-critical systems were described in (Babeshko, 2009), (Kharchenko, 2010), (Illiashenko, 2010), (Yu, 2009).

On different stages of programming evolution the researches in comparison of program packages for reliability and safety analysis were done by (Bowles, 1990), (Brall, 2007), (Li, 2008) and others.

\subsubsection{Requirements to reliability and safety analysis} application

Several standards and other normative documents describing analysis procedure and containing requirements to reliability and safety analysis and recommendations regarding assessment were analyzed:

- IEC 61508: 2010. Functional safety of electrical/electronic/programmable electronic safety related systems;

- IEC 61513: 2001. NPPs - I\&Cs important to safety general requirements for systems;

- IEC 60880: 2006. NPPs - I\&Cs important to safety SW aspects for computer-based systems performing category A functions;

- IEC 60812: 2006. Analysis techniques for system reliability - Procedure for failure mode and effects analysis (FMEA);

- Mil-Std-1629A: 1980. Procedures for performing a failure mode, effects and criticality analysis;

- NP 306.5.02/3.035: 2000. Requirement on nuclear and radiation safety to I\&Cs important to safety in NPPs (Ukraine);

- Telcordia (Bellcore) SR-332, Issue 1. Reliability Prediction Procedure for Electronic Equipment;

\subsubsection{Safety Case development and application}

Aspects of system safety control and reliability are described in (Goble, 2010). Safety assessment procedure for safety-critical systems is described in (Yangyang, 2006). Various examples of methodologies of Safety Case development described in (Bishop 1998) and Eurocontrol's DAP/SSH/091 show varied approaches to understanding of Safety Case development. Decision-making system based on safety using cost-benefit analysis is described in (Rae, 2010).

\subsection{The aim of work}

The aim of this work is to develop a methodology (based on new type of safety cases) of choice of the most appropriate technique for safety analysis and tool (or tools) which could cover safety analysis requirements for a particular task.

\subsection{The structure of work}

This paper consists of 5 sections. In section 1 motivation and the substantiation of aim are presented. This section outlines problem of insufficient relation between safety analysis techniques and tools that cover them.

Section 2 presents developed approach of safety cases constructing, presents notation. This section provides a sequence of requirements assessment and illustrates new detailed safety case approach.

Section 3 describes several safety analysis techniques, their features and possibilities of complexation.

In section 4 criteria for choice of software tools and techniques, procedure of choosing and choice optimization using mathematical apparatus are described.

Section 5 briefly describes a software tool which is a software implementation of proposed technique of T\&T choosing.

Finally, we make conclusions and outline future work in this field.

\section{SAFETY CASE - ORIENTED TECHNIQUE \\ 2.1 General approach}

To develop safety systems it is necessary to use documented assurance of the achievement and maintenance of safety - Safety Cases.

We propose General Safety Case approach based on package of interconnected activities and which allows answering the questions: What (to-do) - using Project information, How (to-do) using Project requirements and Wherewith (to-do) using Decision-making system.

General WHW-Safety Case approach is presented in Fig.1 and it shows the general way of compliance to requirements assessment beginning with requirements (and/or constraints) defining and finishing with exit report which will be the answer the question "Whether project is in compliance with the requirements?"

\subsection{Notation}

To build a Safety Case using our approach we develop a new notation which consists of several types of blocks or units and lines or arrows. Nomenclature of WHW - notation is presented in Fig. 2 .

Proposed general approach with WHW-notation could be used to build a new type of Safety Cases and would help to answer the question "How, What and Wherewith should we do to receive a right results? (i.e. that are in compliance with requirements)

\subsection{Sequence of assessment}

The sequence of estimation and logic is described underneath. Detailed General WHW-Safety Case approach is shown in Fig.3.

Project requirements are divided into Functional and Nonfunctional requirements which in their turn are subdivided into Product and Process requirements. All requirements are organized in Requirement profile.

Then Requirement profile is formalized and the Requirements set is organized. Block "Standards" is not a part of closed system because regulatory documents could change from project to project. 


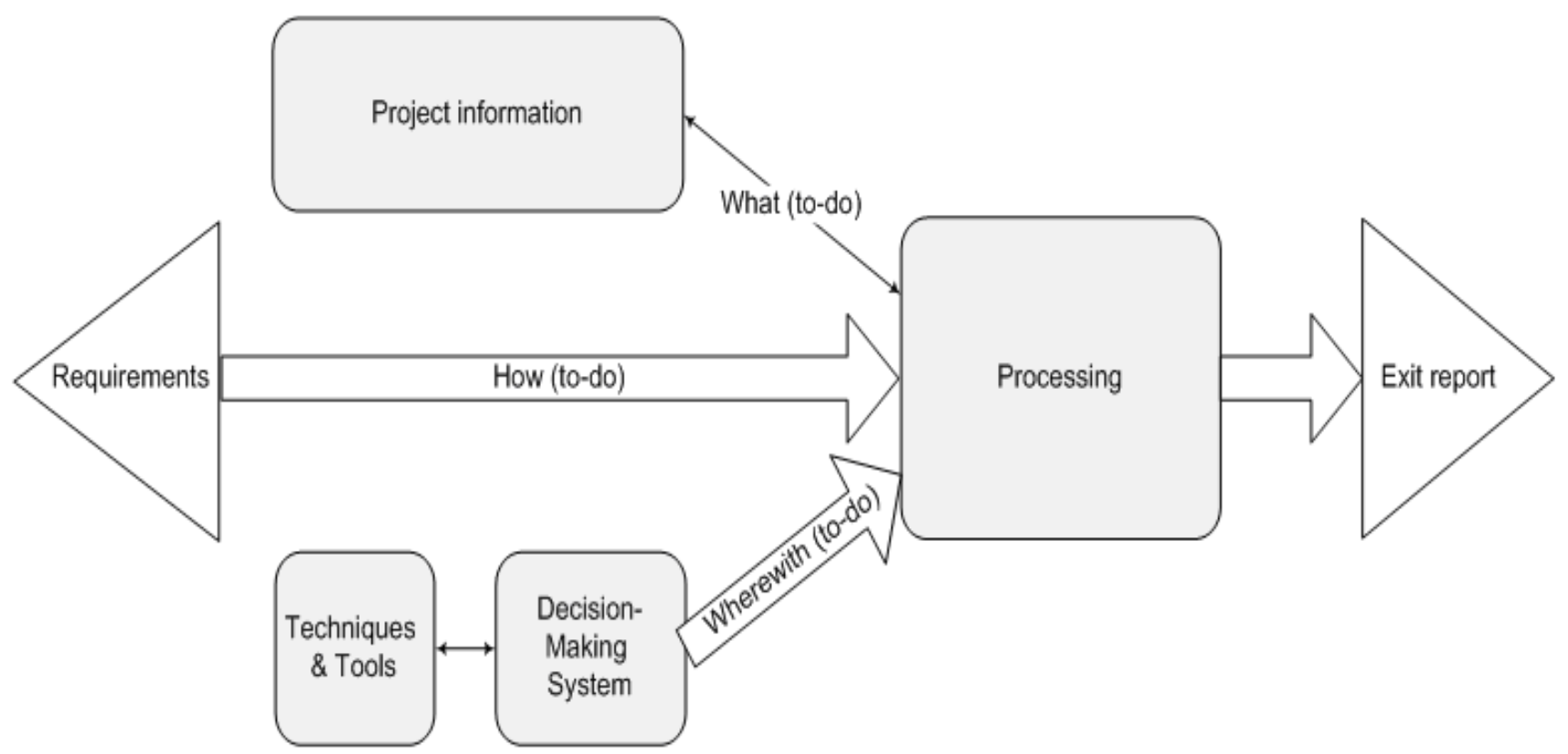

Fig 1 General WHW-Safety Case approach

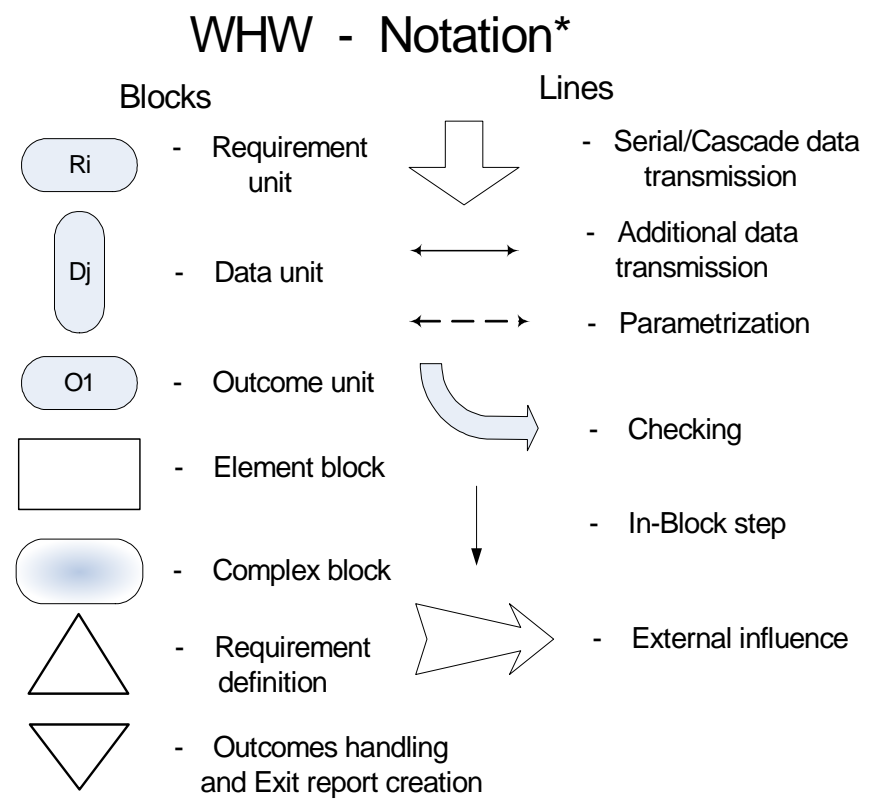

Fig.2 Elements of WHW-notation

Standards play role of external regulator to closed systems. Requirements with Standards describe system's behavior using "How (to-do)?" question.

Project information consists of the following blocks:

a) Documentation;

b) Code;

c) Testing Reports;

d) Others (any other relevant information that could be used in project)

Project information describes system's behavior using "What (to-do)?" question.
Project information formalized and a project data organized in Data set.

Besides, a special part of Case is Assessment Case. This block consists of 2 interconnected blocks:

- Tools (which consists of tools for reliability and safety analysis);

- Methods and techniques (used for analysis).

Requirement set, Data set and Assessment Case are connected with "Tool for Decision-Making" block. And this information is an input data for Decision Making. DecisionMaking System describes system's behavior using "Wherewith (to-do)?" question.

The next step is data processing. The result of work of Decision-Making System is Outcomes set which would be compared with parameterized Project information. Then next step is Data handling and exit report creation.

General approach could be widely used with different Cases for assessment so-called "Subcases."

\section{TECHNIQUE OF COMPLEXATION}

There are a lot of well-known techniques that can be used for NPP I\&CS dependability analysis and assessment of its attributes. Using these techniques it is possible to perform quantitative and/or qualitative assessment. Every assessment method or technique has its own pros and cons. For high-quality analysis of the estimated objects these techniques should be used in combination with each other. For time-reducing factor, because most of analysis techniques are quite complicated, a certain amount of tools that support reliability and safety analysis techniques were developed. 


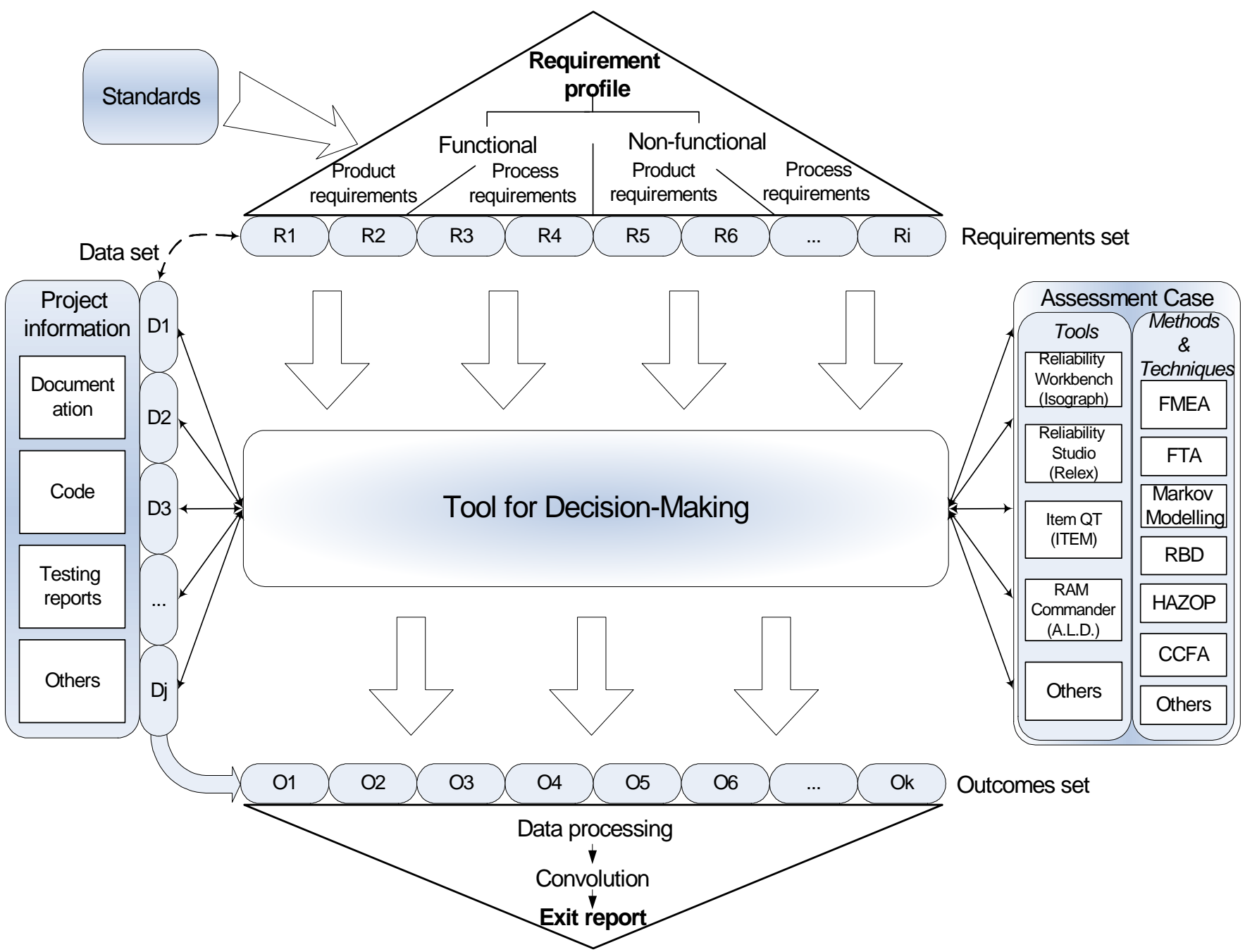

Fig.3 Detailed General WHW-Safety Case approach applied to safety analysis tools and techniques

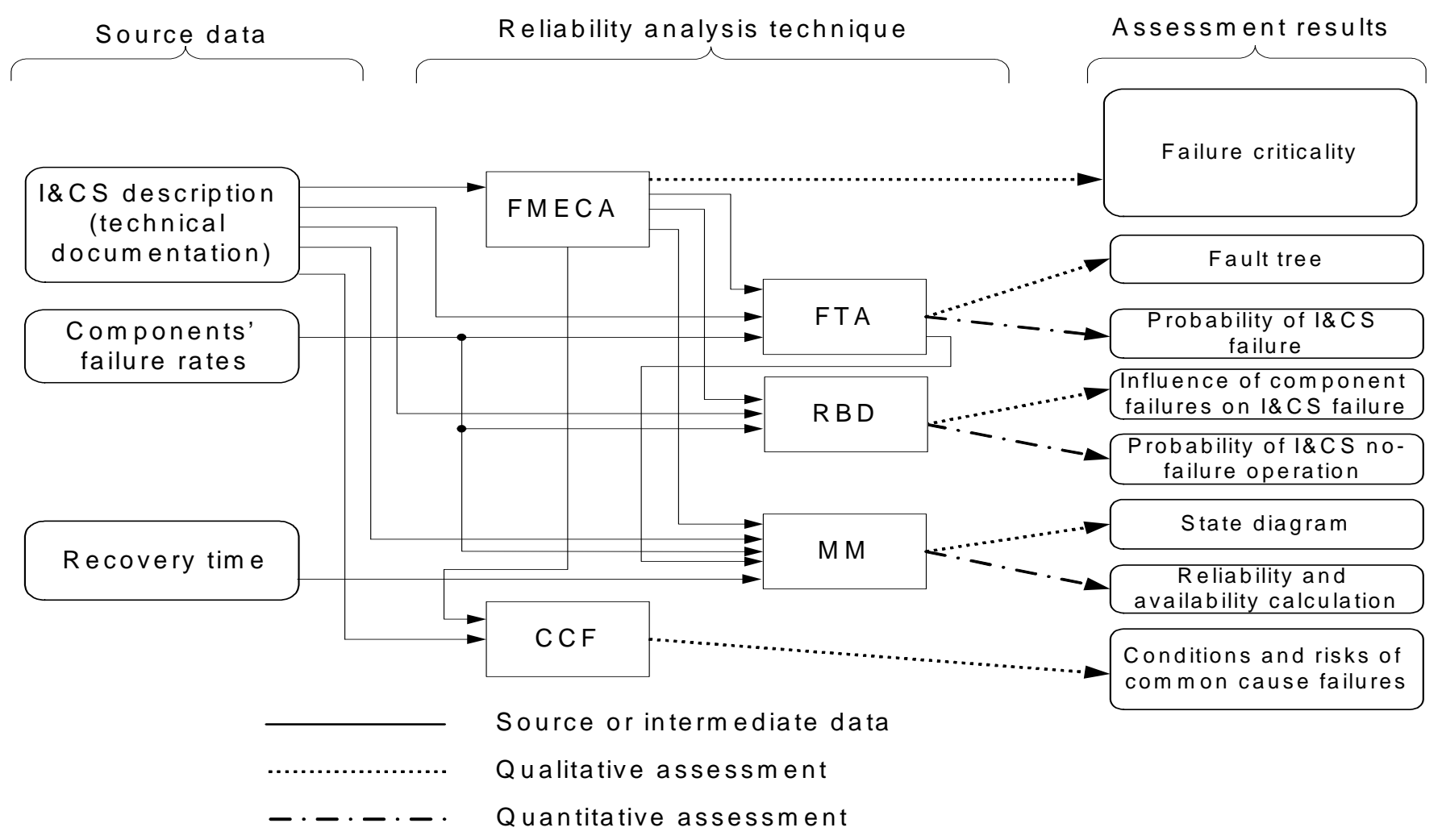

Fig.4 Combined usage of reliability analysis techniques 
Therefore, qualitative use of reliability and safety analysis is reduced to:

a) complexation of known techniques

b) use of one or several tools which support these techniques.

Results of possible combination of techniques are shown in Fig. 4.

FMECA is carried out early in the NPP I\&CS development life cycle to find ways of mitigating failures and thereby enhancing reliability through design and it is not sufficient to use only FMECA during NPP I\&CS analysis.

Results of FMECA and IMEA are used during further FTA (Fault Tree Analysis), RBD (Reliability Block Diagram), CCF (Common Cause Failure Analysis), and also during Markov Modeling.

During RBD it is possible to use list of all components that can cause I\&C system failure which has been obtained during FMECA.

To applying FTA results of FMECA are used to get list of all possible failures.

To perform Markov modeling it is required to know component's failure rates and recovery time so as to get state-to-state transitions.

Finally in most cases the NPP I\&CS operation may be analyzed using a Markov model.

\section{TOOL CHOICE}

\subsection{Choice criteria}

The following criteria for analysis and comparison were used and their features are described as following:

\subsubsection{Compliance to normative documents}

Nowadays most of companies work for standardization of their productions and software compliance to international standards is the cornerstone of technique and tool choice. The meaning of "compliance" is exact maintenance of requirements and functions described in document.

This criterion is divided to following:

a) International ISO/IEC standards;

b) Guidance/procedures;

c) National standards;

d) Industry standards;

e) Other normative documents.

Criteria listed above were selected to understand which software products are oriented to international (projectindependent) needs and which are oriented to individual customers.

\subsubsection{Experience of application in industry}

Field of software application in industry partially could show industrial area that software would cover.

\subsubsection{Methods used for assessment of system NPP I\&C} safety

This criterion shows techniques, indexes, functions, etc. which results could be automatically calculated using reliability software.

\subsubsection{Tool architecture/framework}

Tool architecture largely determines the possibility of flexibility in using the software. The analysis showed that currently the following types of architectures are presented:

a) Desktop system (1 PC);

b) Server system;

c) Web-based system;

d) Multi-user system (2 or more computers).

\subsubsection{Reporting}

Report about work that was done, its correctness, the right calculation of results, understandability are very important when using the results of the program. This criterion shows the possibility of saving data in certain file formats or it representation in the form of a report.

\subsubsection{Vendor support}

Almost all companies provide customer support by phone, using webinars, e-mail correspondence, or by fax. Free technical support is available for a certain period (usually no more than 4 months).

\subsection{Choice optimization}

To solve choice task of most appropriate tool and technique we need to use mathematical apparatus.

The sequence reasoning and corresponding mathematical transformations are described below:

a) There is a set of techniques for reliability and safety analysis:

$$
\text { MTechniques }=\left\{\text { Technique }_{i}\right\}_{i=1}^{n_{\text {Tech }}}
$$

(e.g. FMECA, FTA, HAZOP, etc.);

b) There is a set of tools:

$$
\text { MTools }=\left\{\text { Tool }_{j}\right\}_{j=1}^{m_{\text {Tool }}}
$$

(e.g. Reliability Studio, FMEA-Pro, RAM Commander, etc.);

c) Every tool has it's quantitative and qualitative characteristics (or criterion as previously determined):

$$
\text { Tool }_{j} \sim\left\{X_{1 j}, \ldots X_{r j}\right\}
$$

(e.g. compliance to normative documents, reporting, vendor support, etc.)

And every characteristic has a set of constraints:

$X_{v j}=\{\alpha, \ldots, \zeta\}$

d) There is such tool, which includes a set of techniques from MTechniques set:

$\forall$ Tool $_{j} \sim \Delta_{j}$ MTechniques

e) There is an indicator, that indicates an existence of certain characteristic in according tool:

$$
\gamma_{j k}=\{0,1\}
$$

(" 0 " - characteristic is not available, " $1 "-$ characteristic is available);

f) For more pictorial rendition let's build a Boolean matrix (Tool-Technique). An example of Boolean matrix is shown in Table 1: 
Table 1 An example of "Tool-Technique" matrix

\begin{tabular}{|c|c|c|c|c|c|}
\hline \multicolumn{2}{|c|}{} & \multicolumn{5}{|c|}{ Tools } \\
\cline { 3 - 6 } \multicolumn{2}{c|}{} & Tool1 & Tool2 & Tool3 & Tool4 \\
\hline \multirow{4}{*}{ Techniques } & Technique1 & $\underline{\mathbf{1}}$ & $\underline{\mathbf{1}}$ & 0 & 0 \\
\cline { 2 - 6 } & Technique2 & 0 & $\underline{1}$ & $\underline{1}$ & 0 \\
\cline { 2 - 6 } & Technique3 & $\underline{1}$ & 0 & 0 & $\underline{1}$ \\
\cline { 2 - 6 } & Technique4 & 0 & 0 & $\underline{1}$ & 0 \\
\hline
\end{tabular}

g) Thus forming a verbal task:

"It is necessary to choose one or several tools Tool" from MTools set and such which cover MTechniques set and provide and optimal criterion value (e.g. cost)";

h) There can be different combinations of characteristics $X$ for coverage task solving. They are listed below:

$X_{1 j} \geq X_{\text {required }}$, e.g. "MTTF must be more then 50000 hours";

$X_{2 j} \leq X_{\text {assessed }}$, e.g. "Time of analysis must be less than 30 minutes";

$X_{3 j} \in X_{l}$, e.g. "Average probability of failure on demand, must be calculated as part of IEC 61508 compliance";

$X_{r j} \rightarrow \min$ - Optimality condition (e,g, "The lowest cost")

i) We'll solve task from Table 1 and define more appropriate Technique and Tool. As optimality condition we will use cost of tool.

First we'll write a function using discrete mathematics from Boolean matrix:

$$
\begin{aligned}
& F=\left(T_{1} \cup T_{3}\right) \cap\left(T_{1} \cup T_{2}\right) \cap\left(T_{2} \cup T_{4}\right) \cap T_{3}= \\
& =\left(T_{2} \cup T_{1} \cap T_{4}\right) \cap T_{3}=T_{2} \cap T_{3} \cup T \cap T_{3} \cap T_{4}
\end{aligned}
$$

The formula (7) in fact is Conjunctive Normal Form.

Now we receive 2 sets of Tools:

$$
\Delta M * T_{1}=\left\{T_{2}, T_{3}\right\}, \Delta M * T_{2}=\left\{T_{1}, T_{3}, T_{4}\right\}
$$

Next step is choosing of set that meets optimality criteria (that has the lowest cost).

\subsection{Stages of procedure}

So, now we'll put in order every activity to receive a universal algorithm. Selection of T\&T is carried on according with the following steps:

a) Defining task in verbal form;

b) Formalizing task using mathematical apparatus.

c) Task solution

- Stage 1: building of Table.

Deciding how many and what tools and techniques will be compared. Example is provided in Table 2, it shows appropriate tools and criteria mostly for RBD, FTA and FMEA-analysis (and theirs modifications). During work on this paper, many software tools for reliability and safety analysis, as well as many techniques were analyzed. We decided to show exactly these criteria because they are determinant (if not even main) for choice. Many existing international standards and regulative documents regarded to safety analysis in different spheres of industry are shown in Table 2. Criteria that were analyzed are described in section 4 (Tool Choice), part 4.1 (Choice criteria).

- Stage 2: Boolean matrix isolation («matrix ToolsTechniques»)

Results of analysis of T\&Ts are presented in matrix form ("Tools-Techniques"), (Table 1).

- Stage 3: select the optimal set of task solutions.

Task is being solved using discrete mathematics apparatus.

- Stage 4: selection from optimal set of solutions by criterion.

Defining the criterion (e.g. cost) and selection the most appropriate variant.

\section{DECISION-MAKING SYSTEM 'SUPPORT+PLUS"}

The proposed technique is implemented as special tool for decision making. This tool consists of database of tools and techniques, database of standards, logic modules of T\&T choosing, graphical interface, etc.

The proposed technique was used for development of company standard CStd 66 (RPC Radiy, 2010). This guide contains requirements and procedures of FMECA analysis of developed and produced NPP I\&C systems based on RADIY platform.

\section{CONCLUSIONS}

In this paper an approach of "technique of techniques' choosing" for NPP I\&C systems safety assessment is proposed. Also tool "Support+Plus" that implements methodology of decision-making was developed

It is planned to create more universal decision making system based on described tool. We are planning to refine developed safety case approach and create a unified methodology.

\section{REFERENCES}

Babeshko, E., et al, 2009, Radioelectronic and computer systems, Vol. 40, pp 60-64.

Illiashenko, O., et al, 2010, Radioelectronic and computer systems, Vol. 48, pp 283-287.

Kharchenko, V., et al, 2010, ICAPP'10

Goble, W, 2010, "Control Systems Safety Evaluation and Reliability”, 3rd ed., ISA Press, 550.

Yangyang, Yu, et al, 2006, RAMS-2006, pp 588-593.

Bowles, J., et al, 1990, Annual Reliability and Maintainability Symposium, pp 450-455.

Brall, A., et al, 2007, RAMS-2007, pp 119-124.

Li, M., et al, 2008, RAMS-2008, pp 86-90.

McEllin, M., 2010, SCSC Newsletter, Volume 20, Number 10, pp 5-7.

Rae, A., 2010, SCSC Newsletter, Volume 20, Number 10, pp 8-11.

Bishop, P., et al, 1998, Industrial Perspectives of SafetyCritical Systems, SCSS, pp 2-10.

RPC Radiy Company Standard, CStd. 66, Reliability Analysis. Failure Modes, Effects and Criticality Analysis (FMECA), 2010, 30 p. 
Table 2 Example of matrix for FMECA-based assessment

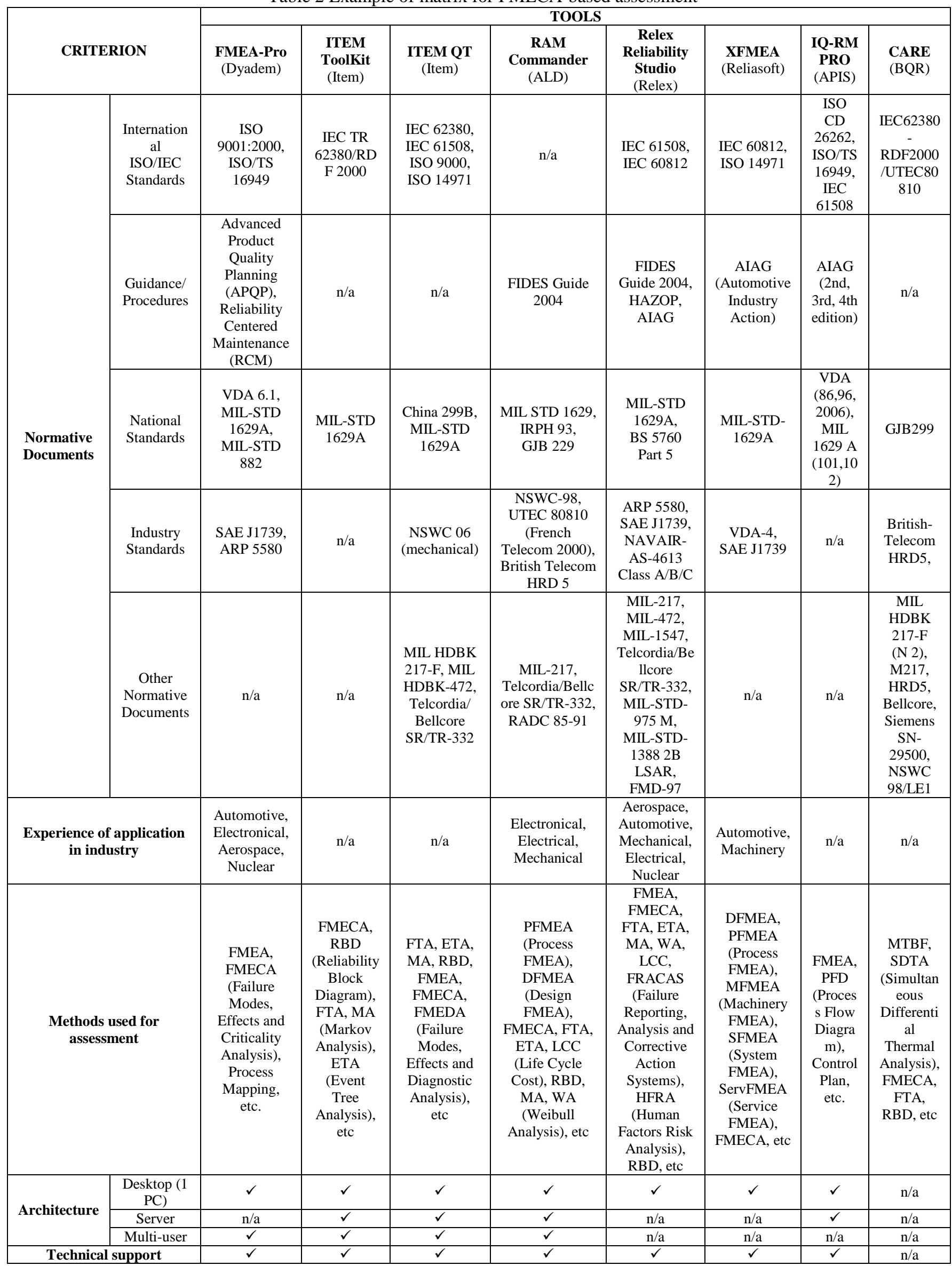

